\title{
RUANG KESADARAN DIALEKTIK, MAMPANG PRAPATAN, JAKARTA SELATAN
}

\author{
Angelita Permatasari Angkola ${ }^{1)}$, Alvin Hadiwono ${ }^{21}$ \\ 1)Program Studi S1 Arsitektur, Fakultas Teknik, Universitas Tarumanagara, angel.angkolaa@gmail.com \\ ${ }^{2)}$ Program Studi S1 Arsitektur, Fakultas Teknik, Universitas Tarumanagara, alvinhadiwono@ymail.com
}

Masuk: 20-01-2021, revisi: 21-02-2021, diterima untuk diterbitkan: 26-03-2021

\begin{abstract}
ABSTRAK
Hidup ditengah hiruk piruknya modernisasi perkotaan, gaya hidup yang tinggi, kondisi lingkungan yang padat, dan tuntutan pekerjaan membuat orang merasakan tekanan secara psikologis hingga semakin bertambahnya risiko stres terhadap masyarakat perkotaan. Selain itu, kemajuan teknologi yang pesat menyebabkan masyarakat metropolitan lebih mudah mendapatkan stressor (situasi penuh tekanan). Halini menyebabkan semakin sulitnya individu untuk menghadapi stres karena tuntutan sosial, ekonomi, dan lingkungan yang terus mempengaruhi di sekitar kita. Apabila mengalami stres berkepanjangan dapat mengakibatkan gangguan jiwa ringan seperti depresi dan gangguan kecemasan. Stres perkotaan tidak hanya disebabkan oleh kondisi personal seseorang namun juga dapat disebabkan oleh perkotaan yang tidak didukung dengan sarana dan prasarana untuk kenyamanan psikologis di perkotaan. Oleh sebab itu, proyek "Dialectic Healing Space - Ruang Kesadaran Dialektik" ini berusaha untuk mewujudkan ruang yang menjadi tempat untuk "terapi" dari berbagai kepenatan dan kesibukan perkotaan. Ruang yang dapat menjadi pengekspresian emosi bagi mereka yang mengalami stres. Desain ini mengusulkan wadah rekreasi berupa pengalaman ruang yang dapat mempengaruhi panca indera dan emosi pengunjung melalui berbagai media dialektik yang didedikasikan untuk mencapai proses healing sebagai bentuk dari respon positif membantu mengurangi tingkat stres pada masyarakat metropolitan dengan melakukan pendekatan melalui panca indera, interaksi fisik dan psikologis pengunjung. Rancangan menggunakan pendekatan melalui metode biophilic design.
\end{abstract}

Kata kunci: kesibukan aktivitas kota; metropolitan; stress; tekanan psikologis; wadah rekreasi

\begin{abstract}
Living in the middle of the hustle and bustle of urban modernization, a high city lifestyle, dense environmental conditions, and the demands of work make people feel psychological pressure, so that the risk of stress in urban areas increases. In addition, rapid technological advances make it easier for metropolitan citizen to get stressors (stressful situations). This makes it more difficult for individuals to deal with stress due to social, economic and environmental demands that continue to affect our surroundings. When the citizen often under prolonged stress, it can cause mild mental disorders such as depression and anxiety disorders. Urban stress is not only caused by a person's personal condition but can also be caused by cities that are not supported by facilities and infrastructure for psychological comfort in urban areas. Therefore, the project "Dialectic Healing Space - Ruang Kesadaran Dialektik" seeks to create a space that becomes a place for therapy to various urban fatigue and busyness. A space that can be an emotional expression for those who experience stress. This design proposes is as a recreational space in the form of a spatial experience that can influence the senses and emotions of visitors through various dialectical media dedicated to achieving the healing process as a form of positive response to help reduce stress levels in the metropolitan by approaching the five senses, physical and psychological interactions of visitors.
\end{abstract}

Keyword: dense city activity; metropolitan; psychological; recreational space; stress 


\section{PENDAHULUAN}

\section{Latar Belakang}

Secara etimologis dwelling berasal dari kata kerja to dwell berasal dari kata Inggirs Lama dwellan yang berarti mengembara, menunda, mendiami, tinggal di suatu tempat lebih lama. Sedangkan menurut KBBI berarti tempat tinggal; kediaman yang dihuni. Martin Heideger, dalam bukunya yang berjudul "Building, Dwelling, Thinking" menawarkan sebuah konsep berhuni, di mana terdapat 3 aspek utama dalam definisi berhuni yaitu to stay, to linger, dan to wander. Poin ketiga dari definisi dwelling yaitu to wander; berkelana mencari ketenangan hidup, sering terlupakan dikarenakan masyarakat perkotaan sibuk memenuhi kebutuhan hidup. Hal ini mengakibatkan terabaikannya perhatian terhadap mental health yang kemudian akan memicu stres.

Salah satu permasalahan yang harus dihadapi manusia saat ini adalah tingginya stress ratio pada masyarakat perkotaan yang diakibatkan oleh kepadatan dan kesibukan aktivitas kota. Hidup di tengah perkotaan dengan hiruk piruknya modernisasi, gaya hidup yang tinggi, kondisi lingkungan yang padat, dan tuntutan pekerjaan membuat orang merasakan tekanan hingga semakin bertambahnya risiko stres di perkotaan. Apabila mengalami stres berkepanjangan dapat mengakibatkan gangguan jiwa ringan seperti depresi dan gangguan kecemasan. Stres perkotaan juga dapat disebabkan oleh perkotaan yang tidak didukung oleh sarana dan prasarana untuk kenyamanan psikologis di perkotaan. Hal ini menyebabkan semakin besarnya peluang individu untuk mendapatkan stres karena tuntutan sosial, ekonomi, dan lingkungan yang terus mempengaruhi di sekitar kita.

Oleh karena itu, dalam proyek ini dirancang "Dialectic Healing Space - Ruang Kesadaran Dialektik" untuk mewujudkan ruang yang dapat menjadi tempat untuk "terapi" dari kepenatan dan kesibukan perkotaan. Ruang yang dapat menjadi wadah pengekspresian emosi bagi mereka yang mengalami stres. Rancangan ini mengusulkan wadah rekreasi berupa pengalaman ruang yang dapat mempengaruhi panca indera dan emosi pengunjung melalui berbagai media dialektik yang didedikasikan untuk mencapai proses healing sebagai bentuk dari respon positif membantu mengurangi tingkat stres pada masyarakat metropolitan dengan melakukan pendekatan melaluipanca indera, interaksi fisik, dan psikologis pengunjung.

Dasar dari pengajuan konsep pengalaman ruang dialektik adalah sebagai proses untuk mencapai healing, dengan mengajak audience untuk menyadari dan mencari tahu penyebab dari stres yang sedang dialami. Setelah menemukan penyebab stres yang dialami melalui konsultasi, lalu dapat diproses dengan healing yang tepat melalui berbagai media dialektik yang ditawarkan. Secara sederhana, dialektik dapat diartikan sebagai dua kubuh yang berlawanan namun saling terkait dan terdapat penengah sebagai kubuh netral. Kubuh negatif dapat dimaknai sebagai "proses menyadarkan" dan kubuh positif dimaknai sebagai "proses healing" itu sendiri.

\section{Rumusan Permasalahan}

Berdasarkan latar belakang yang ada, diketahui terdapat beberapa masalah yang terjadi, yaitu:

- Bagaimana proyek Masa Depan Berhuni Berbasis Hari ini: Ruang Kesadaran Dialektik dapat menjadi solusi dan tanggapan dari kebutuhan akan kesehatan mental masyarakat metropolitan?

- Bagaimana isu tingkat stres akibat kesibukan aktivitas kota menjadi potensi penentuan program Masa Depan Berhuni Berbasis Hari ini: Ruang Kesadaran Dialektik yang dapat mereduksi permasalahan kota metropolitan?

\section{Tujuan dan Manfaat \\ Untuk Kawasan}


Dengan terbangunnya proyek dwelling pada suatu kawasan akan memberikan sisi positif bagi para masyarakatnya. Selain faktor sosial, proyek juga ditujukan untuk meningkatkan kualitas hidup masyarakat terutama mental healthnya, dalam proyek ini dimaksud dengan bidang penyembuhan dari sisi psikologis atau pengobatan non medis masyarakat perkotaan. Mereka juga akan lebih sering berinteraksi satu sama lain antara manusia, hewan dan tumbuhan yang merupakan program besar dari rancangan, guna menghasilkan hormon endorfin lebih banyak sebagai pereda nyeri alami tubuh yang diproduksi sebagai respon terhadap stres yang terjadi.

\section{Untuk Kota}

Manfaat pada sektor kota ialah menjadi pusat destinasi baru dalam kota yang kemungkinan besar mayoritas targetnya adalah pekerja generasi milenial dan alpha. Dari segi pencapaian karena berada di dekat pusat ibukota, destinasi akan lebih mudah dicapai dan meningkatkan minat masyarakat untuk datang. Selain itu juga meningkatkan kepekaan pemerintah dan masyarakat akan kebutuhan "a place to escape" dari kesibukan kota yang dapat memicu stres.

\section{Untuk Masa Depan}

Manfaat untuk masa depan adalah dengan Jakarta sebagai kota yang lebih baik dan berkelanjutan dengan menciptakan program yang bertahan hingga tahun - tahun ke depan dan bersifat adaptif akan perubahan yang mungkin nanti terjadi. Rancangan ini diharapkan dapat terus membantu masyarakat metropolitan dalam merespon dengan positif stres yang dialami melalui wadah rekreasi dialektik.

\section{KAJIAN LITERATUR}

\section{Kesehatan Mental}

Kesehatan Mental dapat didefinisikan sebagai terhindarnya seseorang dari keluhan dan gangguan mental baik berupa neurosis maupun psikosis (penyesuaian diri terhadap lingkungan sosial). Istilah "Kesehatan Mental" diambil dengan konsep mental hygiene. Kata "mental" diambil dari bahasa Yunani, pengertiannya sama dengan psyche dalam bahasa latin yang artinya psikis, jiwa atau kejiwaan. (Taylor, 2003)

Mental yang sehat tidak akan mudah terganggu oleh stressor (penyebab terjadinya stres), orang yang memiliki mental sehat berarti mampu menahan diri dari tekanan-tekanan yang datang dari dirinya sendiri dan lingkungannya. Noto Soedirdjo, menyatakan bahwa ciri-ciri orang yang memiliki kesehatan mental adalah memiliki kemampuan diri untuk bertahan dari tekanan-tekanan yang datang dari lingkungannya. (Notosoedirdjo \& Latipun, 2005)

Sedangkan menurut Clausen Karentanan (Susceptibility) keberadaan seseorang terhadap stressor berbeda-beda karena faktor dari genetik, proses belajar dan budaya yang ada dilingkungannya, juga intensitas stressor yang diterima oleh seseorang dengan orang lain juga berbeda. Kesehatan mental pada manusia itu dipengaruhi oleh faktor internal dan eksternal. Keduanya saling mempengaruhi dan dapat menyebabkan mental menjadi sakit, bisa menyebabkan gangguan jiwa danpenyakit jiwa. (Hasan, 2008)

\section{a. Faktor Internal}

Faktor internal adalah faktor yang berasal dari dalam diri seseorang seperti sifat, bakat, keturunandan sebagainya.

b. Faktor Eksternal

Merupakan faktor yang berada diluar diri seseorang yang dapat mempengaruhi mental seseorang. 


\section{Dialektika}

Menurut KBBI, Dialektika adalah hal berbahasa dan bernalar dengan dialog sebagai cara untuk menyelidiki suatu masalah. Menurut Hegel, Dialektika adalah segala sesuatu yang terdapat di alam semesta itu terjadi dari hasil pertentangan antara dua hal dan yang menimbulkan hal lain lagi. Dialektik (Dialektika) berasal dari kata dialog yang berarti komunikasi dua arah, istilah ini telah ada sejak masa Yunani kuno ketika diintrodusir pemahaman bahwa segala sesuatu berubah (panta rei).

Dialektika adalah IImu Pengetahuan tentang hukum yang paling umum yang mengatur perkembangan alam, masyarakat dan pemikiran. Sedangkan metode dialektis berarti investigasi dan interaksi dengan alam, masyarakat dan pemikiran. Hukum umum Dialektika yang ini menyatakan, bahwa proses perkembangan dunia material atau dunia kenyataan objektif terdiri dari dua tahap. Tahap pertama adalah perubahan kuantitatif yang berlangsung secara perlahan, berangsur atau evolusioner. Kemudian meningkat ke tahap kedua, yaitu perubahan kualitatif yang berlangsung dengan cepat, mendadak dalam bentuk lompatan dari satu keadaan ke keadaan lain, atau revolusioner. Perubahan kuantitatif dan perubahan kualitatif merupakan dua macam bentuk dasar dari segala perubahan. Segala perubahan yang terjadi dalam dunia kenyataan objektif itu kalau bukan dalam bentuk perubahan kuantitatif, maka dalam bentuk kualitatif.

Pada dasarnya dialektika digunakan untuk mencari kebenaran dalam teori Socrates maupun Aristoteles. Namun dalam perkembangannya dialektika digunakan oleh Hegel untuk menentang ajaran metafisika. Ajaran Hegel kemudian ditentang oleh Marx dan melahirkan dialektika materialisme.

\section{Stres}

Stres yang berasal dari bahasa latin strictus, merupakan konsep yang komplikatif dan terkadang membingungkan. Sekitar tahun 1600-an, Robert Hooke membuat konsep stres berdasarkan prinsip mekanika dan beban (tenaga eksternal), stres (daerah yang mendapat tenaga). Penelitian tentang stres semula dilakukan untuk menguji bagaimana reaksi makhluk hidupmenggunakan sumber dayanya untuk melawan atau lari dari stimulus yang mengancam, baik menghadapi ketegangan fisik (seperti kesulitan atau emosi negatif yang dihasilkan dari konflik hubungan sosial) (Hasan, 2008).

Menurut studi yang dilakukan oleh Andreas Meyer-Lindenberg, direktur Central Institute of Mental Health di Mannheim, Jerman, penghuni kota besar memiliki risiko stres yang tinggi dibandingkan dengan penduduk kawasan pedesaan, terdiri dari :

- $\pm 40 \%$ depresi

- $\pm 20 \%$ untuk potensi anxiety attact (gangguan kecemasan)

- $\quad 2 x$ lipat potensi schizofrenia

Ricard Watson, seorang penulis asal Inggris, dosen dan futurist yang dikenal dengan bukunya Future Files: A Brief History of The Next 50 Years mengatakan bahwa 50\% dari populasi dunia sekarang secara negatif terkait dengan kesehatan mental (Watson, 2010). Persentase perkiraan stres yang dialami masyarakat metropolis dari riset yang dilakukan Ricard Watson:

- Schizophrenia

- Anxiety disorders $21 \%$

- Mood disorders 39\%

- Depression $40 \%$ 
Menurut penelitian yang dilakukan oleh Savvy Sleeper pada 2019 banyak kota yang penduduknya mengalami tingkat stres tinggi. Tokyo menjadi kota dengan penduduk yang mengalami tingkat ketegangan tertinggi di dunia. Kota Mumbai dan Soul berada di posisi kedua dan ketiga dengan penduduk yang mengalami tingkat ketegangan tinggi. Jakarta berada di urutan keenam sebagai kota paling stres di dunia.

Menurut Savvy Sleeper ada 6 dari 9 faktor utama yang dapat mengukur tingkat stres masyarakat diantaranya :

- Laporan mengenai tijauan karyawan yang mengalami stres

- Laporan mengenai karyawan presenteeism alias gangguan produktivitas

- Laporan mengenai motivasi kerja

- Jam kerja

- Waktu untuk liburan

- Tidur yang cukup dan perjalanan yang ditempuh setiap hari oleh pekerja

Faktanya banyak kota yang meremehkan 7 jam untuk tidur. Kota dengan masyarakat yang kurang tidur mengalami stres yang lebih tinggi. Sementara tingkat stres yang di alami oleh para pekerja lainnya karena kelelahan selama bekerja, juga menjadi faktor tertinggi dari tingkat stres.
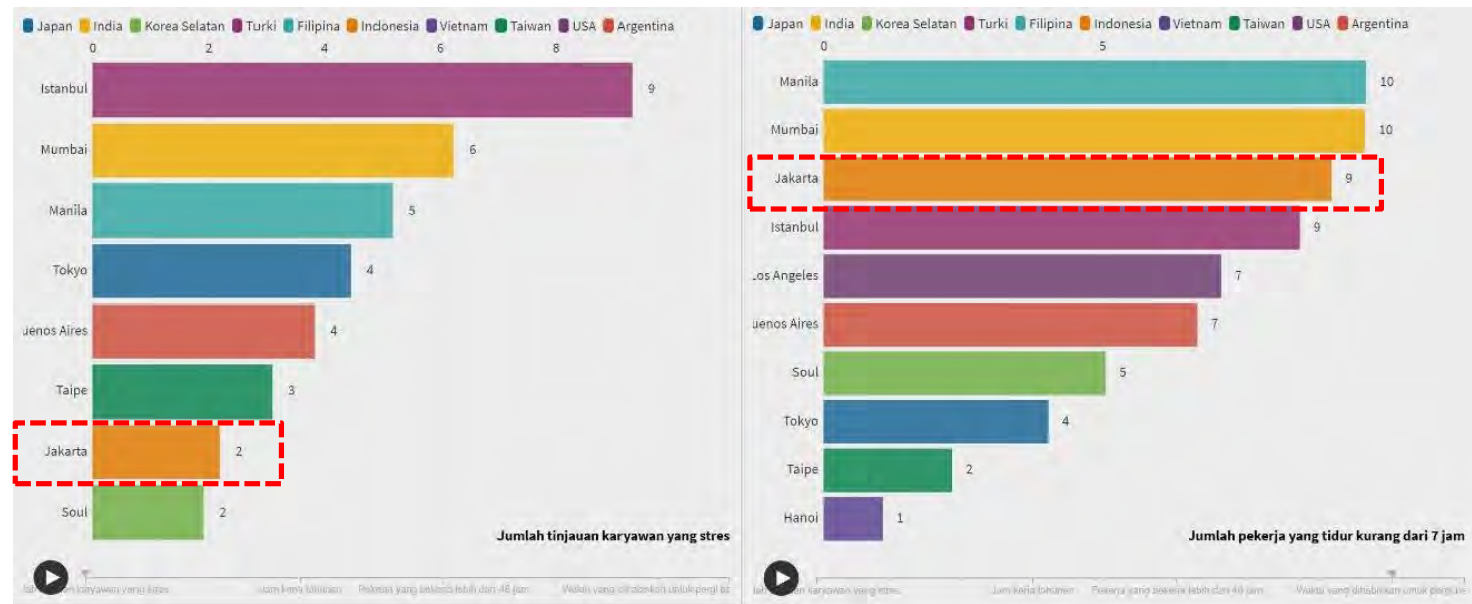

Gambar 1. Jakarta: Kota dengan Tingkat Stress Tertinggi ke 6 di dunia

Sumber : https://data.tempo.co/read/594/jakarta-kota-dengan-tingkat-stress-ke-enam-dunia, (diakses 10/08/20, 13:27 WIB)

Selye dalam Rice menggolongkan stres menjadi dua golongan. Penggolongan ini didasarkan ataspersepsi individu terhadap stres yang dialaminya :

\section{a. Distress (stres negatif)}

Merupakan stres yang merusak atau bersifat tidak menyenangkan. Stres dirasakan sebagai suatu keadaan di mana individu mengalami rasa cemas, ketakutan khawatir, atau gelisah. Sehingga individu mengalami keadaan psikologis yang negatif, menyakitkan, dan timbul keinginan untuk menghindarinya.

\section{b. Eustress (stres positif)}

Bersifat menyenangkan dan merupakan pengalaman yang memuaskan. Eustress juga dapat meningkatkan motivasi individu untuk menciptakan sesuatu, misalnya menciptakan karya seni. Sedangkan variabel yang dapat didefinisikan sebagai penyebab timbulnya stres disebut stressor. Datangnya stressor dapat sendiri-sendiri atau dapat pula bersamaan. Menurut Dr. 
Robert J. Van Amberg sebagaimana dikemukakan oleh Prof Dadang Hawari dalam Sunaryo membagi berbagai tahapan-tahapan stres sebagai berikut:

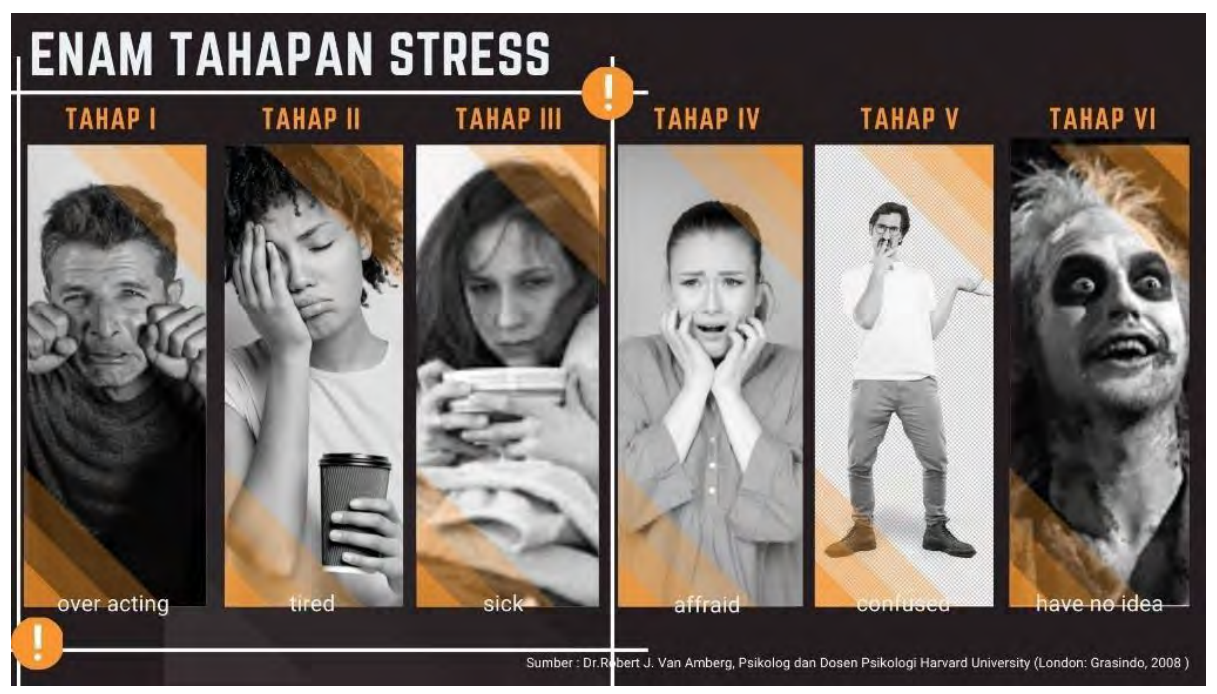

Gambar 2. Tingkat Stres Terdiri dari 6 Tahap

Sumber: Penulis, 2020

\section{Dwelling}

Menurut KBBI berarti tempat tinggal; kediaman yang dihuni. Sedangkan Dwelling secara etimologis berasal dari kata kerja to dwell berasal dari kata Inggirs Lama dwellan yang berarti mengembara, menunda, mendiami, tinggal di suatu tempat lebih lama.

Menurut Martin Heidegger dalam bukunya yang berjudul "Building Dwelling Thinking" kita merasa bertinggal hanya karena adanya sebuah bangunan yang menaungi kita dan konsep dwelling muncul karena kita berhuni atau desain di dunia. Menurutnya tidak semua bangunan adalah tempat tinggal. Bangunan menaungi manusia, menempatinya tetapi bukan tempat tinggal atau bertinggal di dalamnya, jika bangunan ini hanya sebuah tempat naungan. Sehingga dalam artian yang lebih tinggi, manusia dapat mengatakan bahwa ia bertempat tinggal di suatu tempat karena sudah melewati suatu proses yang menyebabkan dia nyaman dan merasa aman untuk tinggal di sana, ini merupakan tingkatan tertinggi dari makna dwelling.

\section{Five Sense}

Dalam bukunya Place Advantege: Applied Psychology for Interior Architecture (2009), Sally Augustin mengatakan bahwa desain dari fisik tempat memengaruhi keadaan mental seseorang dalam ruang tersebut.

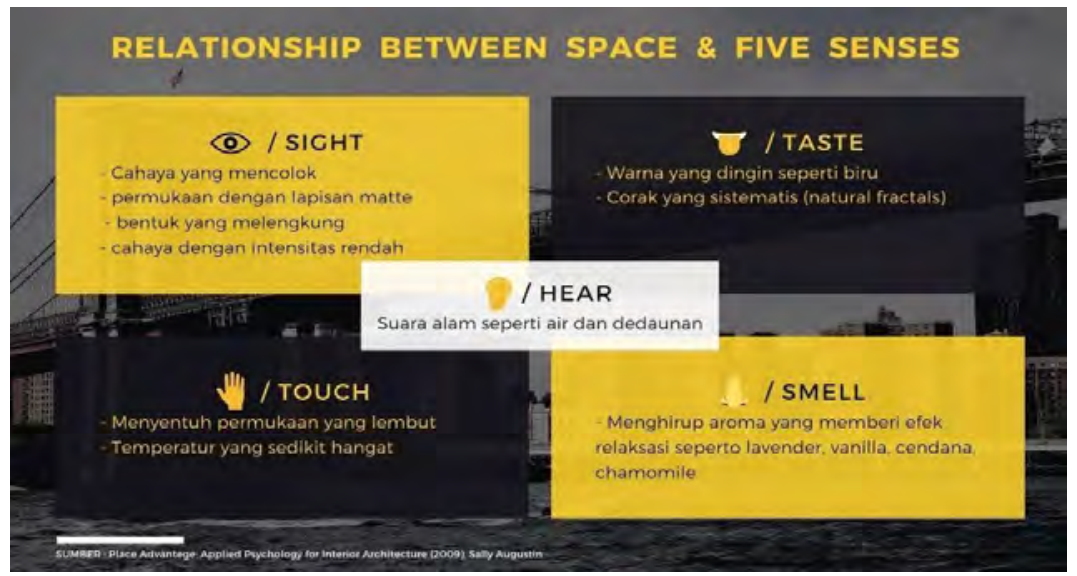

Gambar 3. Hubungan Antara Ruang dan 5 Panca Indera Sumber: Penulis, 2020 


\section{METODE}

\section{Nature and Geometry as Authorities - Biophilic}

"In Architecture in particular, the term is often used to describe forms and patterns inspired by nature" - Asterios Agkathidis, Biomorphic Structures, 2017 (Agkathidis, 2017)

Bimorphic mendapatkan bentuk dari alam yang dapat berupa manusia, tumbuhan, hewan. Dengan bentuk yang menyerupai alam, keharmonisan antar manusia dan alam diharapkan akan terjadi. Selain fungsional, metode biomorphic juga menimbulkan perasaan yang lebih menyenangkan dibanding bangunan dengan metode lainnya. Karena dapat berinteraksi dengan sesama makhluk hidup yang akan meningkatkan hormon endorphin yaitu salah satu hormon kebahagiaan yang berperan dalam meredakan gejala depresi, stres, dan kecemasan saja, tetapi juga melalui pengaruh- pengaruh dari luar yang mempengaruhi desain sepenuhnya. (Calabrese, 2012)

\section{Force Base}

Metode perancangan adalah salah satu langkah yang memungkinkan untuk menyelesaikan permasalahan desain secara optimal. Menurut Plowright, kerangka metodologi arsitektur dibagi menjadi 3 berdasarkan kemunculannya yang berulang. Salah satunya, metode force base. Pola dari perancangan ini tidak hanya berdasarkan pola arsitektural saja, tetapi juga melalui pengaruh- pengaruh dari luar yang mempengaruhi desain sepenuhnya. (Pena, 2001)

Melalui beberapa metode perancangan tersebut, menghasilkan beberapa alternatif gubahan massa yang diperoleh dari ekperimental bentuk dan permainan komposisi bentuk-bentuk geometri hingga menghasilkan 4 gubahan massa yang disesuaikan dengan konsep, program dan kebutuhan ruang yang dinginkan. Dalam proses gubahan massa, proses integrasi karakteristik dialektik dalam gubahan massa beracuan pada program utama rancangan yaitu healing indoor dan healing outdoor. Penulis ingin menawarkan pengalaman healing dari berbagai media dan dimensi ruang, sehingga menciptakan perasaan dan emosi yang berbeda pada tiap-tiap dimensi dan pengalaman ruang.

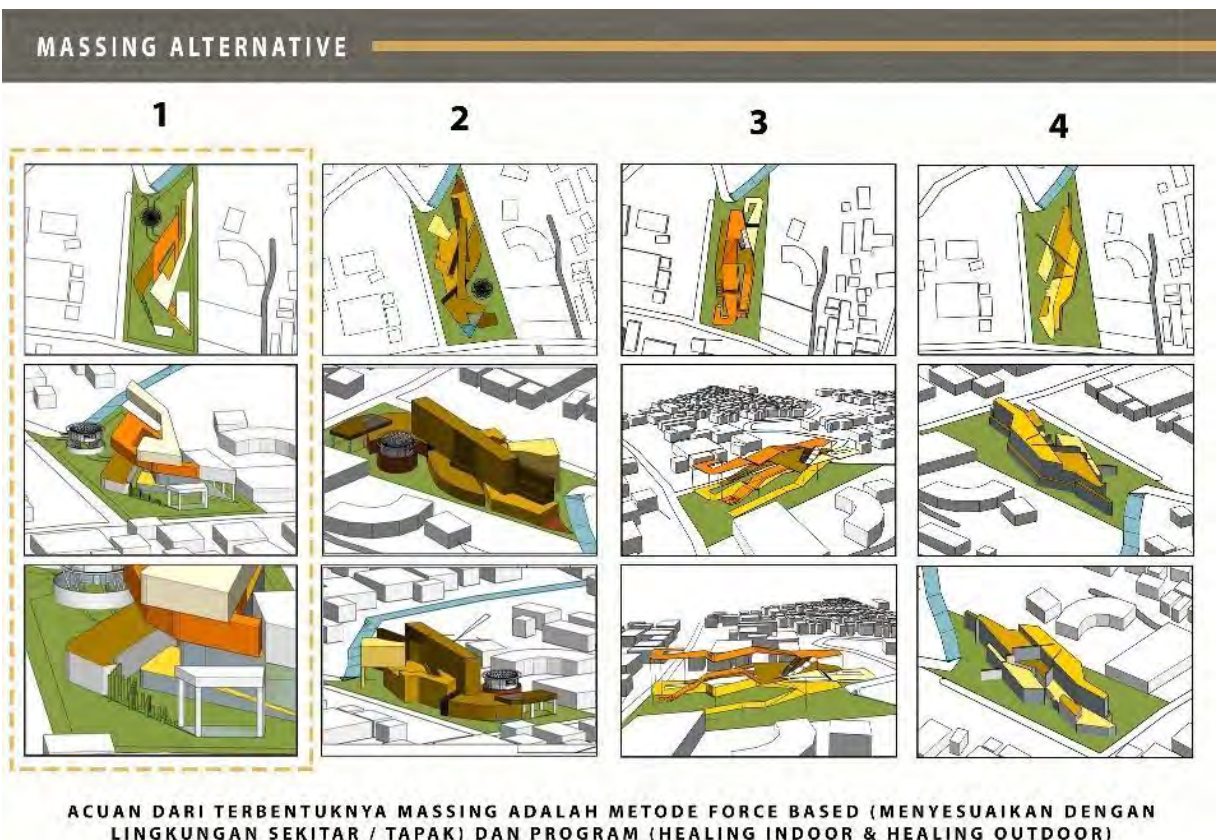

Gambar 4. Massing Alternative

Sumber: Penulis, 2020 


\section{DISKUSI DAN HASIL}

\section{Analisis Lokasi dan Tapak Terpilih}

Lokasi: Jl. Bangka II RT.5/RW.1, Pera Mampang, MampangPrapatan, Jakarta Selatan

Luas: $4.800 \mathrm{~m} 2$

$\mathrm{KDB}: 50 \%$ 目 $2.400 \mathrm{~m} 2$

KLB: 2 ? $9.600 \mathrm{~m} 2$

$\mathrm{KDH}: 4$ 目 $1.680 \mathrm{~m} 2$

KTB: 50

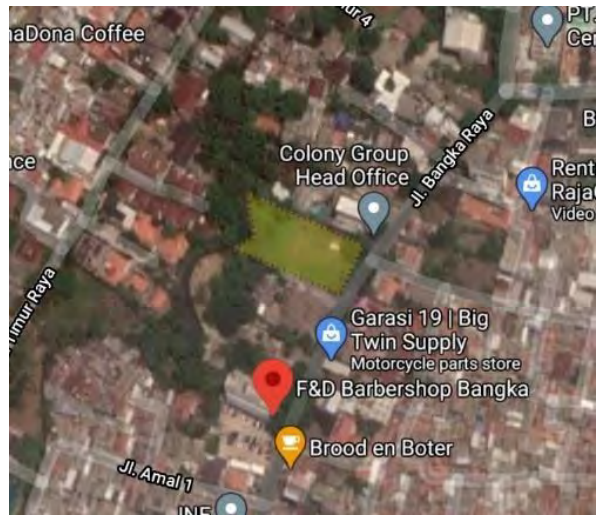

Gambar 5. Peta Lokasi Tapak

Sumber : googlemaps.com, (diakses 23 desember 2020, 14:50WIB)

Penentuan lokasi dilakukan berdasarkan kawasan business district, padat akan aktivitas perkotaan, user targetnya merupakan milenial hingga generasi $Y \& Z$ sehingga dapat mengikuti trend yang berkembang. Jakarta Selatan terkenal sebagai kawasan "tongkrongan" dimana masyarakat metropolitan lebih cenderung melepas kepenatan aktivitas kota dengan kegiatan berkumpul, kuliner dan ketempat-tempat wadah rekreasi lainnya. Lokasi sangat strategis untuk didirikannya proyek yangbertema "wadah rekreasi dialektik".

\section{Konsep Perancangan}

"Dialectic Healing Space - Ruang Kesadaran Dialektik" untuk mewujudkan ruang yang menjadi tempat untuk terapi dari berbagai kepenatan dan kesibukan perkotaan. Ruang yang dapat menjadi pengekspresian dan emosi bagi mereka yang mengalami stres. Desain ini mengusulkan wadah rekreasi berupa pengalaman ruang yang dapat mempengaruhi panca indera dan emosi pengunjung melalui berbagai media dialektik yang didedikasikan untuk mencapai proses healing sebagai bentuk dari respon positif membantu mengurangi tingkat stress pada masyarakat metropolitan dengan melakukan pendekatan melalui panca indera, interaksi fisik dan psikologispengunjung.

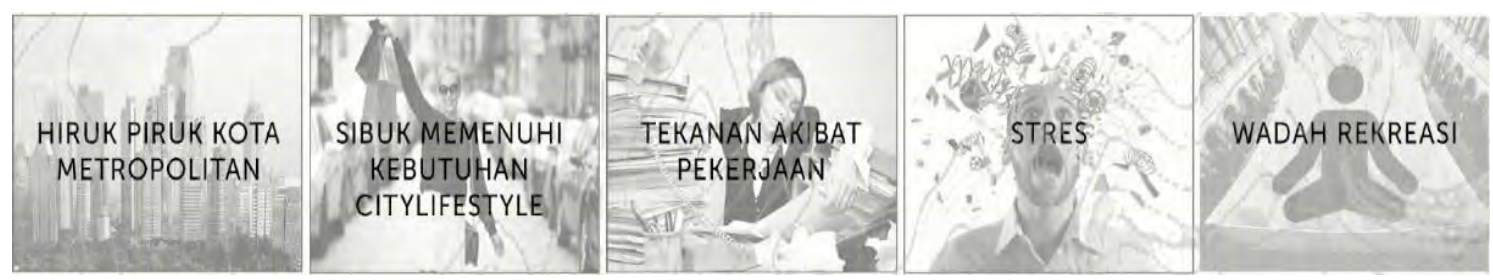

Gambar 6. Skema Ide Dasar Konsep Perancangan

Sumber: Penulis, 2020

Dasar dari pengajuan konsep pengalaman ruang dialectic adalah sebagai proses untuk mencapai healing, dengan mengajak audience untuk menyadari dan mencari tahu penyebab dari stres yang sedang dialami. Setelah menemukan penyebab stres dari konsultasi, lalu dapat direspon dengan healing yang tepat. Dialectic dapat diartikan secara sederhana sebagai dua 
kubuh yang berlawanan namu saling terkait. Kubuh negatif dapat dimaknakan sebagai "proses menyadarkan" dan kubuh positif dapat dimaknai sebagai "proses healing itu sendiri".

Gubahan massa didapatkan melalui eksperimen penyatuan berbagai komposisi objek danjuga menggunakan metode forse base sebagai proses untuk merespon potensi, aktivitas, dan kebiasaan masyarakat setempat. Berikut merupakan gambar-gambar yang dijadikan sebagai representasi dari proses gubahan massa:

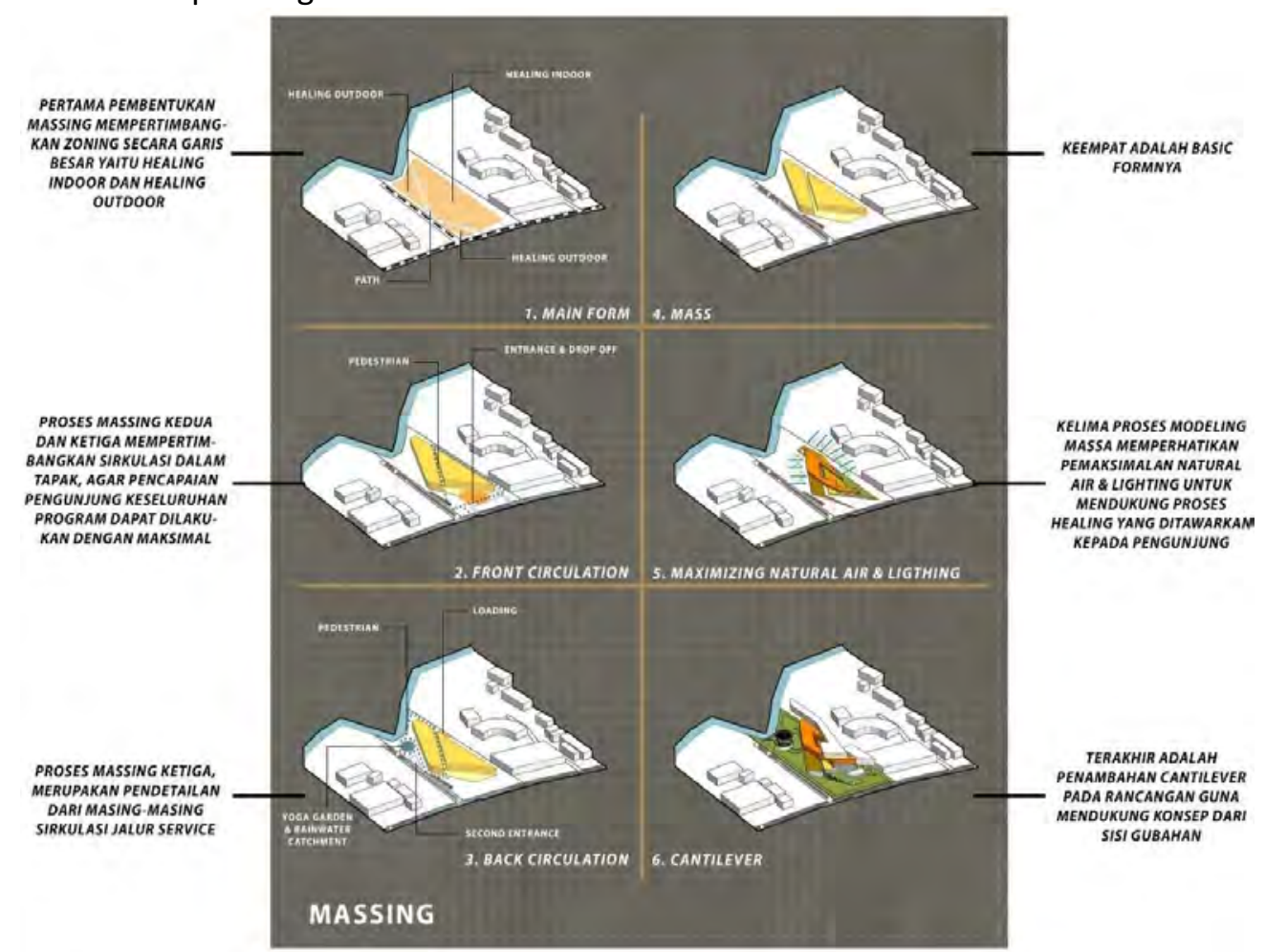

Gambar 7. Transformasi Massa 1-6

Sumber: Penulis, 2020

\section{Detail Program dan Aktivitas Perlantai}

Berikut adalah program yang terdapat pada lantai 1:

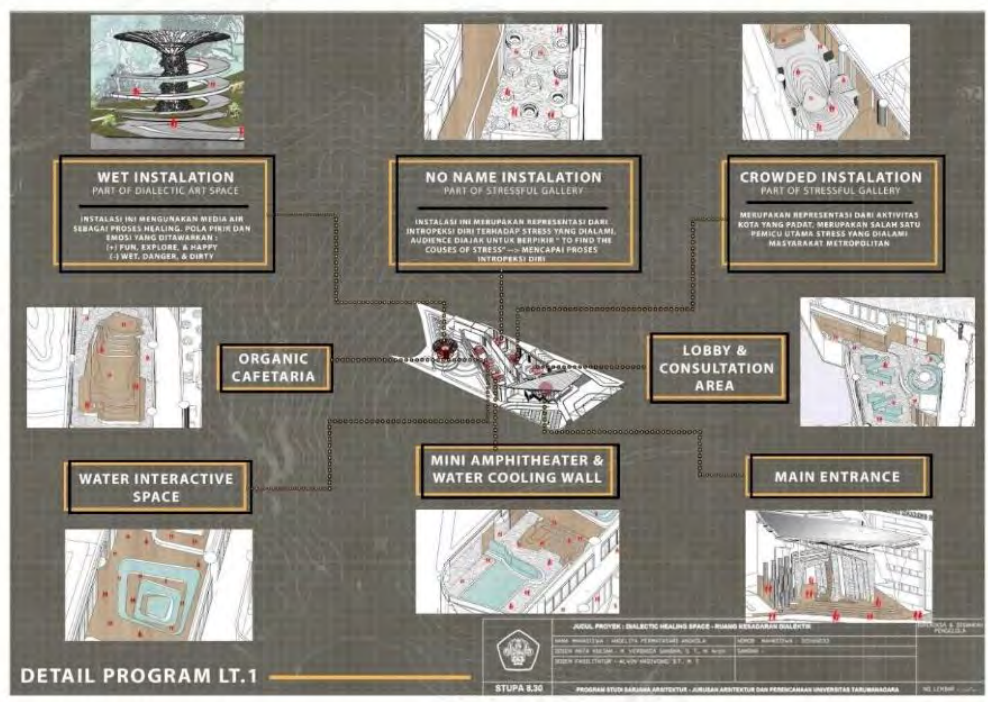

Gambar 8. Detail Program pada Lantai 1

Sumber: Penulis, 2020 
Berikut adalah program yang terdapat pada lantai 2:

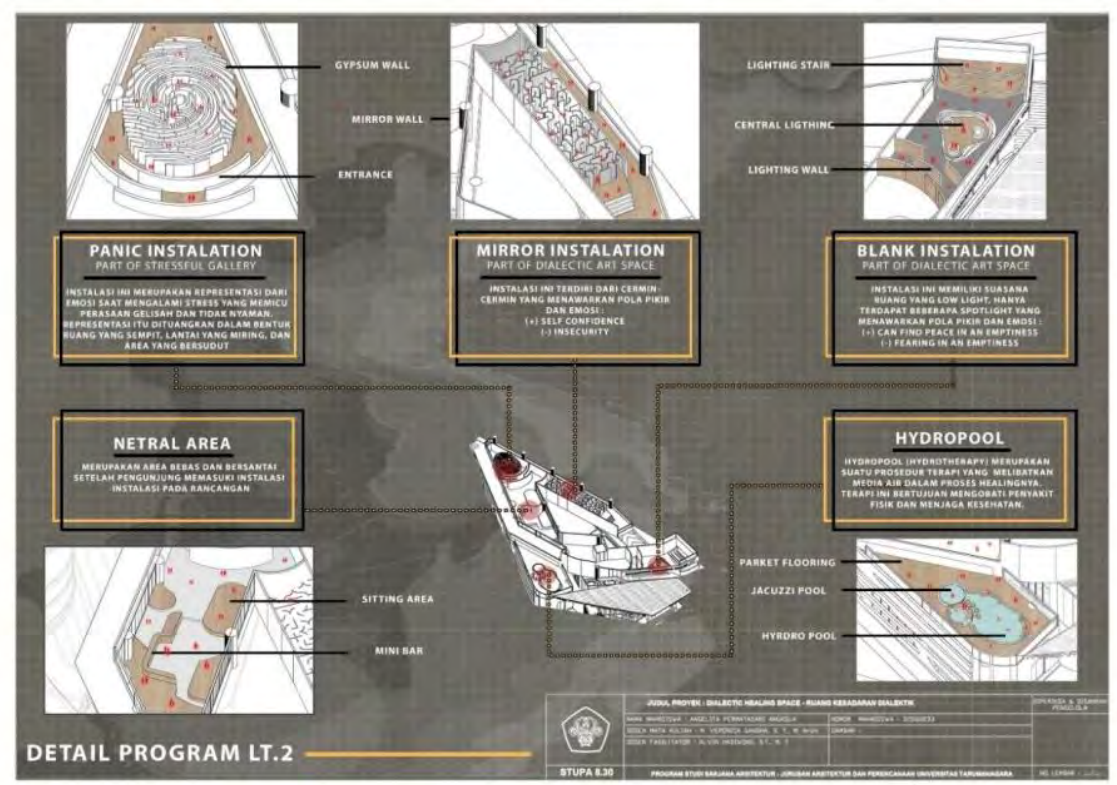

Gambar 9. Detail Program pada Lantai 2 Sumber: dokumen pribadi

Berikut adalah program yang terdapat pada lantai 3:

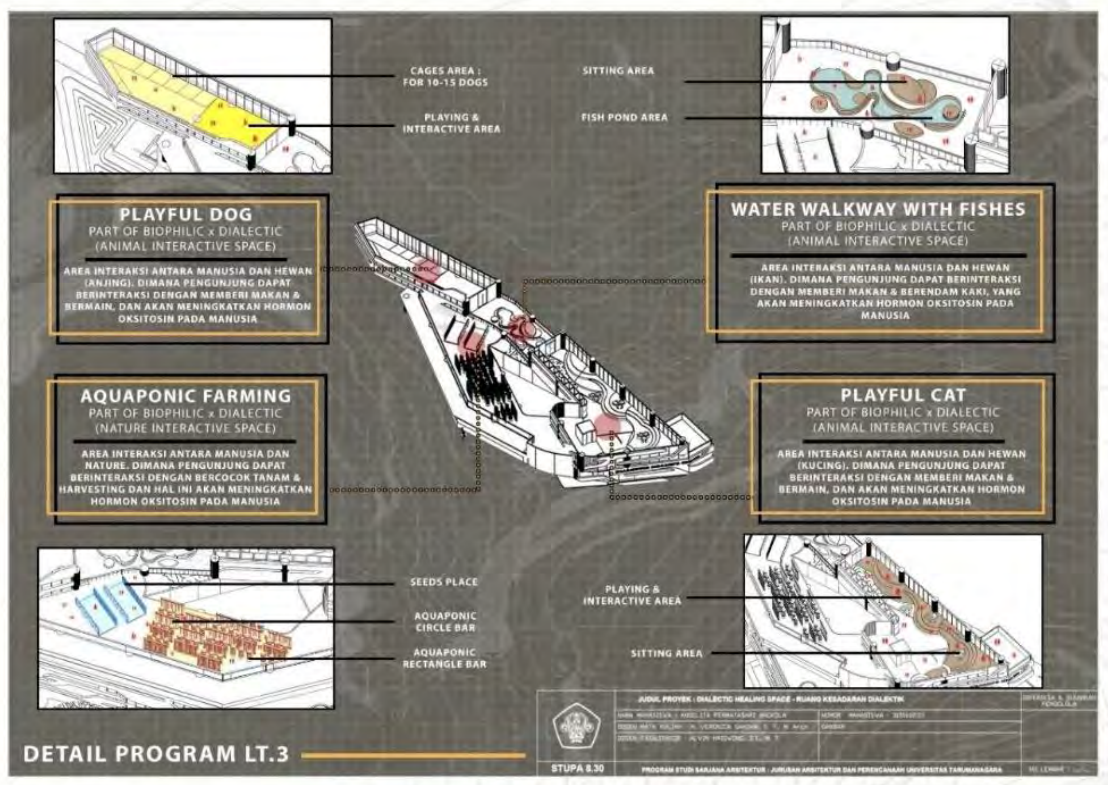

Gambar 10. Detail Program pada Lantai 3

Sumber: Penulis, 2020

\section{Detail Arsitektur}

Dapat dilihat pada gambar 9, dimana terdapat permainan media lantai, dinding dan plafon pada rancangan, guna untuk membuat audience meng explore seluruh ruangan dan memberikan pengalaman ruang yang mempengaruhi pikiran, emosi dan psikologis audience.

Cooling Water Wall merupakan perpaduan antara media air dan teknologi yang digunakan pada program mini amphiteather dan pada area lobby sebagai display terhadap programprogam instalasi yang ada pada rancangan. Perpaduan dari media air sebagai respon terhadap konsep biophilic dan healing dan teknologi merespon kemajuan zaman. Air digunakan sebagai 
dinding layar untuk menampilkan display gambar yang dihasilkan oleh proyektor. Ilustrasi penggunaan cooling water wall dapat dilihat pada gambar 10.

Banyaknya penggunaan media air pada rancangan, guna untuk menciptakan suasana healing, dimana unsur air merupakan salah satu medium positif yang cukup efisien dalam mempengaruhi psikologis dan emosi audience. Unsur air yang dipadukan dengan tumbuhan membuat ruangan lebih terasa dingin, adem, dan asri. Juga membantu memperkaya perolehan oksigen yang maksimal pada setiap ruang sehingga dapat memperlancar peredaran darah manusia dan mempermudah pencapaian proses healing yang diinginkan.



Gambar 11. Potongan Perspektif \& Detail Sumber: Penulis, 2020

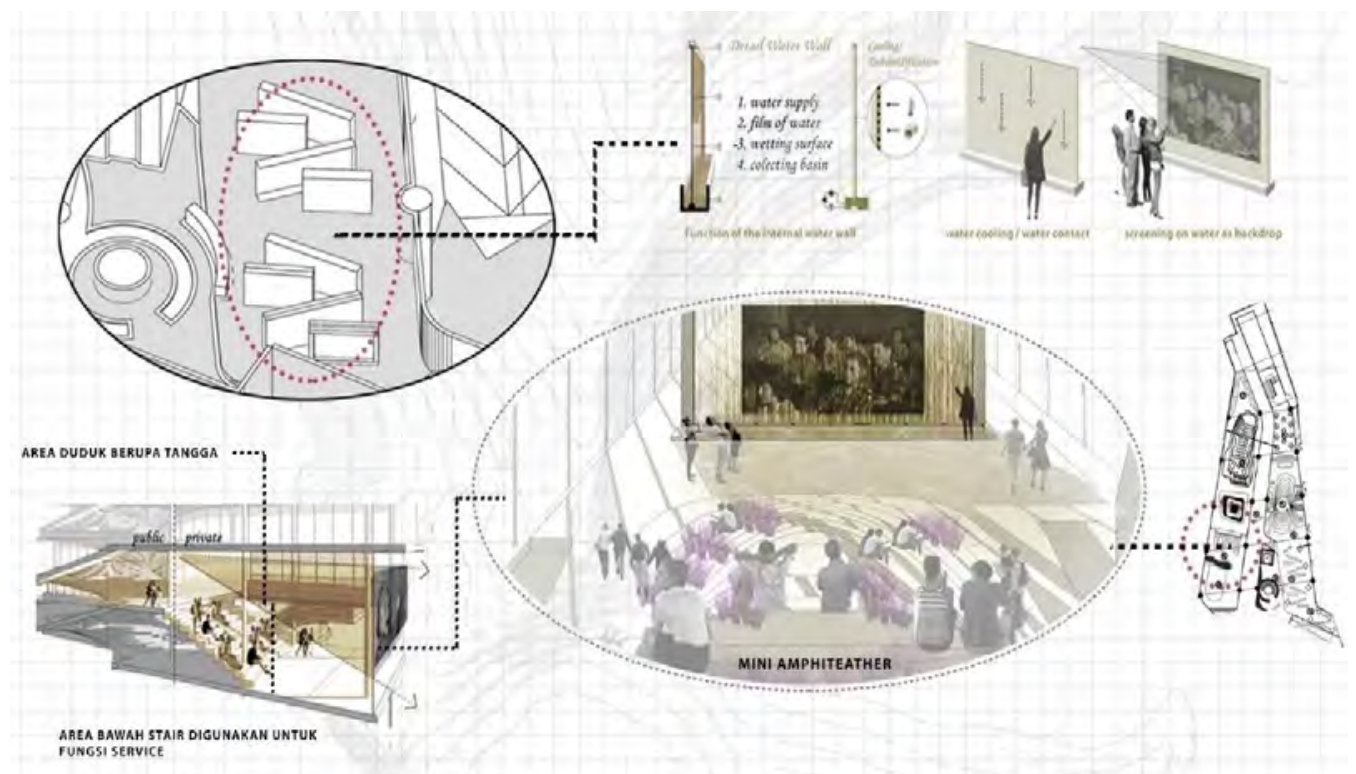

Gambar 12. Detail Arsitektur Cooling Water Wall Sumber: Penulis, 2020 


\section{KESIMPULAN DAN SARAN}

\section{Kesimpulan}

Pada dasarnya, proyek ini berusaha untuk merespon secara positif stres yang dialami masyarakat metropolitan dengan menawarkan sebuah wadah rekreasi berupa pengalaman ruang yang dapat mempengaruhi panca indera dan emosi pengujung melalui berbagai media dialekik yang didedikasikan untuk mencapai proses healing. Oleh karena itu, Ruang Kesadaran Dialektik ini mencoba untuk mewujudkan ruang yang menjadi tempat untuk terapi non-medis dari berbagai kepenatan dan kesibukan aktivitas kota. Ruang yang dapat menjadi pengekspresian emosi bagi mereka yang mengalami stres. Selain itu program- program yang ditawarkan akan disesuaikan dengan tingkat stres yang dialami dan aktivitas yang diinginkan oleh pengujung.

Proyek ini juga berusaha untuk mewadahi masyarakat dari berbagai usia, dengan menciptakan program-program gabungan seperti terapi ruang dengan menekankan persepsi terhadap 5 indera manusia melalui medote desain biophilic dan dialektika, culinary spot, public park sebagai area universal pada rancangan. Usulan rancangan diharapkan dapat memberikan kesempatan untuk membantu masyarakat metropolitan "lepas" dari stres yang dialami, sehingga dapat melakukan kegiatan di perkotaan dengan suasana psiskis yang baik. Selain berusaha memberikan kesan hijau dengan konsep biophilic, rancangan ini diharapkan dapat menjadi tempat yang nyaman untuk dikunjungi kapan pun, dari berbagai umur dan dapat terus membantu masyarakat metropolitan dalam merespon dengan positif stres yang dialami melalui wadah rekreasi dialektik.

\section{Saran}

Perlu adanya kepekaan penduduk metropolitan akan pentingnya menjaga kestabilan kesehatan mental dan psikologis yang sebagian besar selalu diabaikan demi kepentingan duniawi. Sebaiknya kepentingan duniawi dan kepentingan psikologis harus berada pada tingkat yang setara agar masyarakat metropolitan lebih enjoy dan relax dalam melakukan segala aktivitas perkotaan. Karena bagaimanapun upaya arsitektur serta lintas bidang lainnya dalam penyediaan wadah untuk perubahan, tidak akan dapat bekerja dengan baik, karenaperubahan dimulai dari diri manusia sendiri.

\section{UCAPAN TERIMA KASIH}

Penulis mengucapkan terima kasih kepada Dosen Pembimbing, Ketua Jurusan Arsitektur dan Perencanaan, Kaprodi S1 Arsitektur, serta keluarga penulis yang selalu mendukung dalam penyusunan artikel ilimiah ini.

\section{REFERENSI}

Agkathidis. A. (2017). Biomorphic Structures. London : Laurence King Publishing

Calabrese. E. F., Kellert. S. R. (2012). The Principles and Benefits of Biophilic Design. The Practice of Biophilic Design, 01, 6-19.

Hasan. (2008). Pengantar Psikologi Kesehatan. Jakarta: Grasindo

Notosoedirdjo \& Latipun. (2005). Kesehatan Mental, Konsep dan Penerapan. Jakarta: EGC

Pena, W. M. (2001). Problem Seeking: An Architectural Programming Primer. Hoboken, N.J. : Wiley

Taylor. (2003). Health Psychology. New York: MeGraw Hill.

Watson, R. (2010). Future Files: A Brief History of The Next 50 Years. London : Nicholas Brealey 